\title{
Prevalence of Non-Communicable Diseases and its Associate Factors among Government Employees in Biratnagar, Nepal
}

\author{
Roshan Neupane, ${ }^{1}$ Tulsi Ram Bhandari ${ }^{1}$ \\ 'School of Health and Allied Sciences, Faculty of Health Sciences, Pokhara University, Kaski, Nepal.
}

\section{ABSTRACT}

Introduction: Non-communicable diseases have along duration and slow progression. It is estimated that the attribution of NCDs in mortality has been rising gradually in Nepal. This study aimed to estimate the prevalence and factors associated with NCDs in Biratnagar, Nepal.

Methods: A cross-sectional study was conducted among government employees in Biratnagar, Nepal from August to December 2016. We used self-administrated modified WHO STEPS survey questionnaire and distributed to all government employees of Biratnagar Sub-Metropolitan. We used complete filled 323 questionnaires to analyze and draw the results.

Results: The prevalence of NCDs was found 72 (22.3\%). Hence, 322 (99.6\%)government employees had exposed at least one established risk factor of the NCDs. The prevalence of use of any type of tobacco products was $60(18.5 \%)$ and consumption of alcoholic products was 187 (57.9\%). More than two-thirds respondents answered that they consumed fruits once a week. Most government employees consumed vegetable regularly.The majority 193 (59.6\%) respondents used motorcycle and electric rickshaw as means of transportation. Out of the total participants $60(18.6 \%), 19(5.9 \%)$, and $6(1.9 \%)$ reported hypertension, diabetes, and cardiovascular diseases respectively.

Conclusions: Prevalence of Non-Communicable Diseases has been seen in Government Employees in Biratnagar, Nepal. Most of them had at least one associated factor related to NCD was found.

Keywords: government employees; non-communicable diseases; risk factors; WHO STEPS survey.

\section{INTRODUCTION}

Non-communicable diseases (NCDs) are the leading cause of mortality and morbidity worldwide. Cardiovascular diseases, diabetes, cancers and chronic respiratory diseases are dominants. ${ }^{1}$ It hits the hardest groups and decreased the productivity, prolong disability and diminish resources. ${ }^{2}$ Globally, NCDs are estimated to cost more than US $\$ 30$ trillion over the next 20 years, representing $48 \%$ of global gross domestic product in $2010 .{ }^{1,2}$

Annually, NCDs kill 7.9 million people in South-East Asia Region (SEAR). The deaths are expected to be increased by $21 \%$ over the next decade. ${ }^{3,4}$ The greatest increases will be in Africa, SEAR and Eastern Mediterranean by over $20 \% .5,6$ Sixteen million NCD deaths occur before the age of 70 ; out of those deaths, $82 \%$ occurred in low and middle-income countries. ${ }^{7}$

In Nepal, the prevalence of chronic heart disease and hypertension was $5.7 \%$ and $22.7 \%$ in eastern Nepal in $2005 .{ }^{8}$ This study aimed to estimate the prevalence and factors associated with NCDs in Biratnagar, Nepal.

Correspondence: Dr. Tulsi Ram Bhandari, School of Health and Allied Sciences, Faculty of Health Sciences, Pokhara, Nepal. Email: tulsib2004@gmail.com, Phone: +977-9851240961. 


\section{METHODS}

A cross-sectional study was conducted among government employees of Biratnagar Sub-Metropolitan from August to December 2016. The study population of the study was all government employeesof Biratnagar Sub-Metropolitan. The validated WHO STEPS instrument version 2.2 translated in Nepali by Nepal Health Research Council (NHRC) was adopted for collecting the information. ${ }^{9}$ The ethical approval was obtained from the Institutional Review Committee of Pokhara University. Similarly, written permission was taken from District Administrative Office, Morang and informed consent were also mentioned in the self-questionnaire. Modified STEPS survey questionnaire was self-administrated on the census population 538 for the study. Out of total distributed, only $323(60 \%)$ respondents returned the complete filled questionnaire. The collected data were entered into Epi-data 3.1 and analyzed using SPSS 16.0 version. We performed descriptive analysis considering thesocio-demographicstatus of the respondents and risk factors of the NCDs. We further applied chi-square test to examine the association between NCDs and its associated factors.

\section{RESULTS}

Amongst 323 government employees, 92 (28.5\%), $108(33.4 \%)$, and $60(18.6 \%)$ had the history of the NCDs: high blood pressure, diabetes and cardiovascular disease respectively. Similarly, among the health examined government employees 60 (18.6\%), 11
(5.9\%), and 1 (1.9\%) had reported the NCDs: high blood pressure, diabetes and cardiovascular disease respectively. Similarly, nearly one-fifth $(22.3 \%)$ had a prevalence of at least one NCDs among the government employees (Table 1, Figure 1).

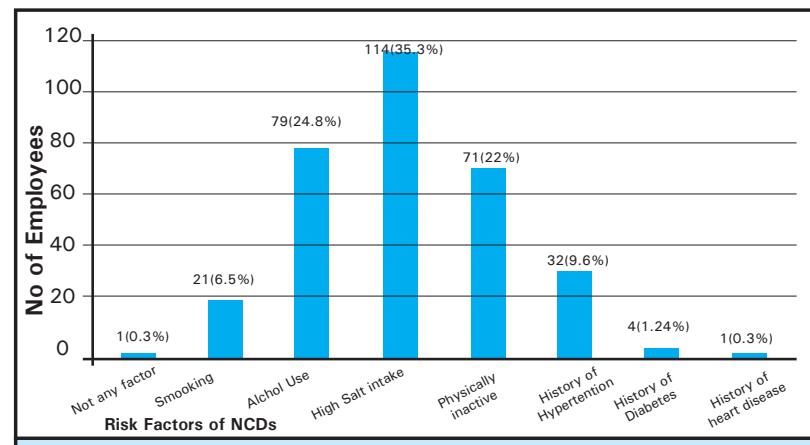

Figure 1. Distribution number of risk factors of NCDs: not any factor, smoking, alcohol use, high salt intake, physically inactive and history of high blood pressure, diabetes and heart disease among government employees.

Table 1. Prevalence of NCDs (high blood pressure diabetes and CVD) among government employees.

\begin{tabular}{ll|}
\hline Prevalence of NCDs & $\mathrm{n}(\%)$ \\
Hypertension & $60(18.6)$ \\
Hypertension and diabetes mellitus & $11(3.4)$ \\
$\begin{array}{l}\text { Hypertension, diabetes mellitus and } \\
\text { cardio vascular diseases }\end{array}$ & $1(0.3)$ \\
Any type NCDs & $72(22.3)$ \\
\hline
\end{tabular}

\begin{tabular}{|c|c|c|c|c|c|}
\hline \multirow[t]{2}{*}{ Risk factors } & \multicolumn{2}{|c|}{ Hypertension } & \multirow[t]{2}{*}{ Total } & \multirow[t]{2}{*}{$\mathrm{X}^{2}$ Value } & \multirow[t]{2}{*}{$P$ value } \\
\hline & Yes n (\%) & No n (\%) & & & \\
\hline \multicolumn{6}{|l|}{ Smoking } \\
\hline Yes & $16(30.8)$ & $36(69.2)$ & 52 & 6.092 & $<0.05^{*}$ \\
\hline No & $44(16.2)$ & 227 (83.8.) & 271 & & \\
\hline \multicolumn{6}{|l|}{ Alcohol use } \\
\hline Yes & $45(54.1)$ & $142(75.9)$ & 187 & 8.845 & $<0.01^{\dagger}$ \\
\hline No & $15(11)$ & 121 (89) & 136 & & \\
\hline \multicolumn{6}{|l|}{ Hard exercise } \\
\hline Yes & $33(17.5)$ & $156(82.5)$ & 189 & 0.375 & 0.540 \\
\hline No & $27(20.1)$ & 107 (79.9) & 134 & & \\
\hline \multicolumn{6}{|l|}{ Medium exercise } \\
\hline Yes & $50(16.8)$ & $248(83.2)$ & 298 & $6.759^{\ddagger}$ & $<0.05^{*}$ \\
\hline No & $10(40)$ & $15(60)$ & 25 & & \\
\hline \multicolumn{6}{|l|}{ Sitting duration in a day } \\
\hline Median and below & $29(19.1)$ & $123(80.9)$ & 152 & 0.094 & 0.759 \\
\hline Above the median & $30(17.8)$ & $139(82.2)$ & 169 & & \\
\hline \multicolumn{6}{|c|}{ History of high blood pressure } \\
\hline Yes & $18(19.6)$ & $74(80.4)$ & 92 & 0.083 & 0.773 \\
\hline No & $42(18.2)$ & $189(81.8)$ & 231 & & \\
\hline
\end{tabular}

${ }^{*} P$ value significant at $a<0.05,{ }^{\dagger}$ at $a<0.01,{ }^{\ddagger}$ Likelihood ratio 
Neupane et al. Prevalence of Non-Communicable Diseases and its Associate Factors among Government Employees in Biratnagar, Nepal

Out of six common risk factors: smoking, alcohol use, hard exercise, medium exercise, history of hypertension, sitting duration in a day, three factors were found significantly associated ( $P$ value: $<0.05)$ with hypertension. Smoking, alcohol use and medium exercise were to be foundstatistically associated ( $P$ value $<0.05$ ) with high blood pressure (Table 2). Similarly, those factors also found to be associated $(P<0.05)$ with diabetes (Table 3$)$. But none of those factors were found statistically associated $(P<0.05)$ with cardio-vascular diseases (Table 4).

\begin{tabular}{|c|c|c|c|c|c|}
\hline \multirow[t]{2}{*}{ Risk factors } & \multicolumn{2}{|l|}{ Diabetes } & \multirow[t]{2}{*}{ Total } & \multirow[t]{2}{*}{$\mathrm{x}^{2}$ Value } & \multirow[t]{2}{*}{$P$ value } \\
\hline & Yes n (\%) & No n (\%) & & & \\
\hline \multicolumn{6}{|l|}{ Smoking } \\
\hline Yes & $7(13.5)$ & $45(86.5)$ & 52 & $6.431^{\dagger}$ & $<0.05^{*}$ \\
\hline No & $12(4.4)$ & 259 (95.6) & 271 & & \\
\hline \multicolumn{6}{|l|}{ Alcohol use } \\
\hline Yes & $16(8.6)$ & $171(91.4)$ & 187 & $5.735^{\dagger}$ & $<0.05 *$ \\
\hline No & $3(2.2)$ & $133(97.8)$ & 136 & & \\
\hline \multicolumn{6}{|l|}{ Hard exercise } \\
\hline Yes & $10(5.3)$ & $179(94.7)$ & 189 & 0.288 & 0.592 \\
\hline No & $9(6.7)$ & $125(93.3)$ & 134 & & \\
\hline \multicolumn{6}{|l|}{ Medium exercise } \\
\hline Yes & $15(5)$ & $283(95)$ & 298 & $3.635^{\dagger}$ & $<0.05^{*}$ \\
\hline No & $4(16)$ & $21(84)$ & 25 & & \\
\hline \multicolumn{6}{|l|}{ Sitting duration in a day } \\
\hline Median and below & $9(5.9)$ & $143(94.1)$ & 152 & $<0.001$ & 0.999 \\
\hline Above the median & $10(5.9)$ & $159(94.1)$ & 169 & & \\
\hline \multicolumn{6}{|l|}{ History of hypertension } \\
\hline Yes & $8(7.4)$ & $100(92.6)$ & 108 & 0.682 & 0.409 \\
\hline No & $11(5.1)$ & 204 (94.9) & 215 & & \\
\hline
\end{tabular}

${ }^{*} P$ value significant at $a<0.05,{ }^{t}$-Likelihood ratio

\begin{tabular}{|c|c|c|c|c|c|}
\hline \multirow[t]{2}{*}{ Risk factors } & \multicolumn{2}{|c|}{ Cardiovascular disease } & \multirow[t]{2}{*}{ Total } & \multirow[t]{2}{*}{$x^{2}$ Value } & \multirow[t]{2}{*}{$P$ value } \\
\hline & Yes n (\%) & No $n(\%)$ & & & \\
\hline \multicolumn{6}{|l|}{ Smoking } \\
\hline Yes & $1(1.9)$ & $51(98.1)$ & 52 & 0.001 & 0.970 \\
\hline No & $5(1.8)$ & $266(98.2)$ & 271 & & \\
\hline \multicolumn{6}{|l|}{ Alcohol use } \\
\hline Yes & $4(2.1)$ & $183(97.9)$ & 187 & 0.198 & 0.657 \\
\hline No & $2(1.5)$ & $134(98.5)$ & 136 & & \\
\hline \multicolumn{6}{|l|}{ Hard exercise } \\
\hline Yes & $4(2.1)$ & 185 (97.9) & 189 & 0.171 & 0.679 \\
\hline No & $2(1.5)$ & $132(98.5)$ & 134 & & \\
\hline \multicolumn{6}{|l|}{ Medium exercise } \\
\hline Yes & $6(2.0)$ & 292 (98) & 298 & 0.976 & 0.323 \\
\hline No & 0 & $25(100)$ & 25 & & \\
\hline \multicolumn{6}{|l|}{ Sitting duration in a day } \\
\hline Median and below & $3(2.0)$ & 149 (98) & 152 & 0.017 & 0.896 \\
\hline Above the median & $3(1.8)$ & $166(98.2)$ & 169 & & \\
\hline \multicolumn{6}{|c|}{ History of high blood pressure } \\
\hline Yes & $3(5.0)$ & 57 (95) & 60 & 3.090 & 0.079 \\
\hline No & $3(1.1)$ & $260(98.9)$ & 263 & & \\
\hline
\end{tabular}


Neupane et al. Prevalence of Non-Communicable Diseases and its Associate Factors among Government Employees in Biratnagar, Nepal

Behavioral characteristics (smoking and alcohol use) of the government employees.

\begin{tabular}{|llll|}
\hline Table 5. Smoking and use of alcohol among government employees. & & \\
\hline Risk factors & Yes $\mathrm{n}(\%)$ & No $\mathrm{n}(\%)$ & Total \\
Smoking & $59(18.3)$ & $264(81.7)$ & 323 \\
Currently smoking any tobacco products & $37(62.7)$ & $22(37.3)$ & 59 \\
Currently smoking any tobacco products daily & $21(35.6)$ & $38(64.4)$ & 59 \\
Tried to stop smoking in past 12 months & $53(16.4)$ & $270(83.6)$ & 323 \\
Ever smoke any tobacco products in past & $37(69.8)$ & $16(30.2)$ & 53 \\
Ever smoke any tobacco products daily in past & $98(30.3)$ & $225(69.7)$ & 323 \\
Currently, use any smokeless any tobacco products & $94(95.6)$ & $4(4.4)$ & 98 \\
Currently use any smokeless any tobacco products daily & $98(30.3)$ & $225(69.7)$ & 323 \\
Ever use any smokeless any tobacco products in past & & & 323 \\
Alcohol use & $187(57.9)$ & $136(42.1)$ & 187 \\
Ever consumed alcohol products & $153(81.8)$ & $34(18.2)$ & 153 \\
Ever consumed any alcohol products in past 12 months & $135(88.2)$ & $18(11.8)$ \\
Consumption of any alcoholic drink within past 30 days & & & \\
\hline
\end{tabular}

\begin{tabular}{|c|c|c|c|c|c|c|}
\hline Type of exercise $(n=323)$ & Yes n (\%) & No n (\%) & Minimum & Maximum & Median & $I^{2} R^{*}$ \\
\hline Hard exercise & $189(58.5)$ & $134(41.5)$ & 1 & 7 & 3 & 2 \\
\hline Medium exercise & $298(92.3)$ & $25(7.7)$ & 1 & 7 & 5 & 2 \\
\hline Heavy recreational exercise & $169(52.3)$ & $154(47.7)$ & 1 & 7 & 2 & 3 \\
\hline $\begin{array}{l}\text { Medium recreational } \\
\text { exercise }\end{array}$ & $175(54.2)$ & 148 (45.8) & 1 & 7 & 3 & 3 \\
\hline $\begin{array}{l}\text { Medium sitting hours in a } \\
\text { day }(n=321)\end{array}$ & & & $2 \mathrm{hrs}$. & 10hrs. & $7 \mathrm{hrs}$. & 3 \\
\hline
\end{tabular}

NCDs conditions and care seeking among government employees.

\begin{tabular}{|c|c|c|c|}
\hline \multicolumn{4}{|c|}{$\begin{array}{l}\text { Table } 7 \text {. NCDs condition and care seeking among } \\
\text { government employees. }\end{array}$} \\
\hline Conditions & $\begin{array}{c}\text { High blood } \\
\text { pressure } \\
\text { n (\%) }\end{array}$ & $\begin{array}{c}\text { Diabetes } \\
\text { n (\%) }\end{array}$ & $\begin{array}{l}\text { Cardiovascular } \\
\text { diseases n (\%) }\end{array}$ \\
\hline History & $92(28.5)$ & $108(33.4)$ & $60(18.6)$ \\
\hline Check-up & $244(75.5)$ & $165(51.1)$ & $94(29.1)$ \\
\hline Presence & $60(18.6)$ & $19(5.9)$ & $6(1.9)$ \\
\hline $\begin{array}{l}\text { Traditional } \\
\text { check up }\end{array}$ & $14(23.3)$ & $8(42.1)$ & $2(33.3)$ \\
\hline $\begin{array}{l}\text { Traditional } \\
\text { medication }\end{array}$ & $14(23.3)$ & $7(36.8)$ & $2(33.3)$ \\
\hline
\end{tabular}

Among 323 government employees, more than thirdfourths $(80.5 \%)$ were male whereas less than one fourth $(19.5 \%)$ were female. Nearly half $(44 \%)$ were of age group 30-44 and second highest $(40 \%)$ were of age group 45-59 with a median age of 40 (IQR-17), the mean age of 40.74 (SD-9.82) with 22 and 58 minimum and maximum age respectively. More than two-thirds $(68.1 \%)$ were upper caste groups whereasminimum $(1.2 \%)$ were religious minorities. out of the total participants, $97.8 \%$ were Hindu and remaining were Muslim and Christians.

The majority $(62.8 \%)$ of government employees were gazette with more than one-third $(37.2 \%)$ were nongazetted. Nearly (31.9) were from middle-income quintile group and one-fifth $(24.7 \%)$ were from the highest income quintile group. More than two-thirds $(67.5 \%)$ completed college education and less than one-third $(23.5 \%)$ completed high school. The median schooling year was 15.7 (IOR-2). Most (86.1\%) were married and few $(10.2 \%)$ were unmarried.

\section{DISCUSSION}


Neupane et al. Prevalence of Non-Communicable Diseases and its Associate Factors among Government Employees in Biratnagar, Nepal

The findings of this study show that the overall prevalence of NCDs (high blood pressure, diabetes and cardiovascular diseases) is $22.3 \%$ and $99.6 \%$ government employees had exposed at least one established risk factor of the NCDs.

Most risk factors, such as current smoking, alcohol consumption, high blood pressure, and low physical activity were prevalent among men than women and both in gazetted and non-gazetted government employees which were similar to the results of Nepal STEPS survey $2013 .{ }^{9} \mathrm{~A}$ study among the urban poor in Kathmandu, Nepal found a high prevalence of behavioral risk factors. ${ }^{10}$

The study showed the prevalence of smoking (18.3\%) among government employees which consistent with the NCD risk factor survey of Nepal 2007/08 and 2013 where the prevalence was $24 \%$ and $19 \%$ respectively. ${ }^{9}$ The prevalence of NCDs is high in Nepal compared with neighbors: India (14\%) and Sri Lanka $(15 \%) .{ }^{11}$ However, it is lower than that in China (28\%), Bangladesh (23\%), Vietnam (24\%), Thailand (24\%) and Russia (39\%) ${ }^{11}$ in the STEPS survey. This highlights the importance of strong implementation and monitoring of the comprehensive Tobacco Control Law 2011. Due to tobacco industry litigation, implementation of the pictorial health warning was implemented only in $2014 .^{9}$

Among the government employees, $18 \% \quad(21.9 \%$ male and $3.2 \%$ female) currently used any tobacco products. Tobacco consumption was high among male compared to female, which could be due to the social unacceptability. ${ }^{9}$ Tobacco used in Nepal is less than in Bangladesh and Myanmar, where around $32 \%$ and $30 \%$ of the adult population used tobacco respectively. Among the tobacco consumer, more than half used smokeless tobacco, and others consumed any types of tobacco. ${ }^{3,12}$ The global targets are to bring tobacco consumption down to less than five percent by 2040 which was declared from the United Nations high-level meeting on NCDs in 2011. ${ }^{13}$ Nepal seems to be far from it. This presents the need for improving people's behavior as it appears to be not changing even when the law exists on the banon the use of tobacco in public places including workplaces and at home.

Use of alcohol, low physical activity and diabetes and hypertension as well as family history of the disease have been also observed as the risk factors NCDs in the government employees of Biratnagar, Nepal. We found about $58 \%$ of the total government employees consumed alcohol which was more among those aged 30 years and above compared to those aged below 30 . Similarly, alcohol consumption was high among gazetted employees than non-gazettedwhich was higher than the prevalence of NCD survey 2013 (two percent) of Nepal. ${ }^{9}$ The proportion of the total population with the use of alcohol was not available in a previous national survey of Nepal. However, in Nepal, the proportion of the current alcohol user male had dropped from $32.3 \%$ in $2007 / 08$ to $11.1 \%$ in $2012 / 13 .{ }^{14}$ The factors affecting the high prevalence of alcohol consumption in government employees warrants further examination, by analyzing the determinants of alcohol use. In comparison to geographical neighbors, this is higher than the prevalence of current alcohol used in Kerala, India where about majority of the population were found to be used alcohol in 2008. ${ }^{15}$ Alcohol consumption among government employees was high which could be due to the practices of providing expensive drinks as a gift from the service takers and also the party with drinks in several meetings, workshops, and conference and hence appears to be a big challenge ahead to reduce its consumption and preventing the population from its adverse effects. ${ }^{14,16}$

The findings of this study showed that more than onethird government employees did not perform the required physical activity. A similar finding was the world health survey where physical inactivity was found to be less prevalent in populations of low socio-economic status, especially in low-income countries ${ }^{17}$ and Nepal NCD survey $2013 .^{9}$ The reason behind it could be due to their busy working hours and sedentary lifestyles. Nearly one in every four government employees had high blood pressure which was similar to results Nepal STEPS survey 2013. ${ }^{9}$ Recent evidence of the high prevalence of hypertension in the government employees and results from another study ${ }^{18}$ underscores that this is a key risk factor and increasing the burden. In 2010, high blood pressure was one of the three leading risk factors for global disease burden and was the leading risk factor for most countries in Asia, North Africa, and the Middle East. ${ }^{19}$ Tobacco smoking, alcohol use, and high blood pressure were more frequent in males than females among government employees which is consistent with findings from a STEPS Survey conducted in Malawi. ${ }^{20}$

The self-reported prevalence of raised blood glucose levels (diabetes) in the current study was $5.9 \%$, which was slightly higher $(4 \%)$ the results of Nepal STEPS Survey $2013^{9}$ and which is less than overall estimates of South Asia (8\%). ${ }^{21}$ This indicates that health services, including primary care services, should be equipped to manage the diabetes cases including screening, diagnosis, treatment and follow up services. Similarly, $1.9 \%$ of the government employees self-reported the prevalence of cardiovascular diseases. Government employees of Biratnagar self-reported that they having high blood pressure, diabetes and cardiovascular disease $28.5 \%, 33.4 \%$ and $18.6 \%$ respectively and 
most of them reported the family history of the same diseases.

Less than one percent of the study population was found to be free of all studied NCD risk factors in the study. This indicates that the burden of NCDs is likely to increase in the future if it is not addressed promptly by the Government of Nepal and other stakeholders. Considering the various risk factors: smoking, alcohol use, physical inactivity, salt intake, high blood pressure, raised blood glucose and family history of NCDs this STEPS survey suggests that NCD risk factors are quite prevalent among the gazetted and non-gazetted government employees. The estimated proportion of deaths due to NCDs in Nepal has been rising from $51 \%$ in 2010 to $60 \%$ in $2014 . .^{3,7}$

This was population-based census study. We used standardized tools for collecting the required information. However, this study covered only quantitative information. Most data were based on the reported information. The human behavior itself is a complex phenomenon. It may need observational empirical information for the precise assessment of the prevalence of risk factors of NCDs among government employees.

\section{CONCLUSIONS}

Almost all government employees were not found to be free of the established risk factors of NCDs and nearly one-fourth government employees were suffered from any NCDS. This indicates that the burden of NCDs is likely to be unbearable burden among the government employees in Biratnagar, Nepal. The behavioral change intervention could be the best solution to minimize the prevalence and associated risk factors of NCDs and its burden in future. Preventing and controlling of the risk factors of NCD may easier and cost-effective strategy in such study population than treatment of NCDs.

\section{ACKNOWLEDGMENTS}

We thank all participants for their co-operation and support during the study. We also acknowledge District Administration Office, Morang for providing permission to conduct this study among government employees. Our sincere gratitude goes to Ethical Review Committee, Pokhara University for granting the ethical approval for this study.

Conflicts of Interest: None.

\section{REFERENCES}

1. Kroll M, Phalkey RK, Kraas F. Challenges to the surveillance of non-communicable diseases-a review of selected approaches. BMC public health. 2015;15(1):1. [PubMed | Full Text]

2. Mohammadzadeh N, Safdari R, Rahimi A. Multi-agent system as a new approach to effective chronic heart failure management: key considerations. Healthc Inform Res. 2013 Sep;19(3):162-6. [PubMed | Full Text]

3. World Health Organization. Non-communicable diseases country profiles 2011[Internet]. Geneva: WHO; 2011 Sep [cited 2017 Nov 10]. [Full Text]

4. Mathers C, Fat DM, Boerma JT. The global burden of disease 2004 update [Internet]. Geneva: WHO; World Health Organization; 2008 [cited 2017 Nov 11]. [Full Text]

5. World Health Organization: Global status report on non-communicable diseases 2010 [Internet]. Geneva: WHO; 2011 Apr [cited 2017 Nov 09]. [Full Text]

6. Alwan A, MacLean DR, Riley LM, d'Espaignet ET, Mathers CD, Stevens GA, Bettcher D. Monitoring and surveillance of chronic non-communicable diseases: progress and capacity in high-burden countries. Lancet. 2010 Nov 27;376(9755):1861-8. [PubMed |DOI | Full Text]

7. Mendis S, Davis S, Norrving B. Organizational Update The World Health Organization global status report on non-communicable diseases 2014; one more landmark step in the combat against stroke and vascular disease. Stroke. 2015 May;46(5):e121-2. [PubMed | Full Text]
8. Vaidya A, Pokharel PK, Nagesh S, Karki P, Kumar S, Majhi S. Prevalence of coronary heart disease in the urban adult males of eastern Nepal: a population-based analytical cross-sectional study. Indian Heart J. 2009 Jul-Aug;61(4):341-7. [PubMed | Full Text]

9. Aryal KK, Mehta S, Neupane S, Vaidya A, Dhimal M, Dhakal $\mathrm{P}$, et al. The Burden and Determinants of Non-Communicable Diseases Risk Factors in Nepal: Findings from a Nationwide STEPS Survey. PloS One. 2015 Aug;10(8):e0134834. [PubMed | Full Text]

10. Oli N, Vaidya A, Thapa G. Behavioural risk factors of non-communicable diseases among Nepalese urban poor: a descriptive study from a slum area of Kathmandu. Epidemiol Res Int. 2013. [Full Text]

11. Giovino GA, Mirza SA, Samet JM, Gupta PC, Jarvis MJ, Bhala $\mathrm{N}$, et al. Tobacco use in 3 billion individuals from 16 countries: an analysis of nationally representative cross-sectional household surveys. Lancet. 2012 Aug;380(9842):668-79. [PubMed | Full Text]

12. World Health Organization. Non-communicable disease risk factor survey, Myanmar (2009). New Delhi: WHO Regional Office for South-East Asia. 2011.[cited 2017 Oct 18]. [Full Text]

13. Beaglehole R, Bonita R, Horton R, Adams C, Alleyne G, Asaria $P$, et al. Priority actions for the non-communicable disease crisis. Lancet. 2011 Apr 23;377(9775):1438-47. [PubMed | Full Text] 
14. World Health Organization. STEPS surveillance: non-communicable diseases risk factors survey. Kathmandu: Ministry of Health and Population, GoN, Society for Local Integrated Development Nepal (SOLID Nepal) and WHO. 2008. [cited 2017 Oct 18]. [Full Text]

15. Sugathan T, Soman C, Sankaranarayanan K. Behavioural risk factors for non-communicable diseases among adults in Kerala, India. Indian J Med Res. 2008;127(6):555. [Full Text]

16. Dhital R, Subedi G, Gurung YB, Hamal P. Alcohol and Drug Use in Nepal. Kathmandu: Child Workers in Nepal Concerned Centre (CWIN). 2001. [Full Text]

17. Hosseinpoor AR, Bergen N, Kunst A, Harper S, Guthold $\mathrm{R}$, Rekve $\mathrm{D}$, et al. Socioeconomic inequalities in risk factors for non-communicable diseases in low-income and middle-income countries: results from the World Health Survey. BMC Public Health. 2012 Oct 28;12:912. [PubMed | Full Text]
18. Vaidya A, Pathak RP, Pandey MR. Prevalence of hypertension in Nepalese community triples in 25 years: a repeat cross-sectional study in rural Kathmandu. Indian heart journal. 2012 Mar-Apr;64(2):128-31. [PubMed | Full text]

19. Lim SS, Vos T, Flaxman AD, Danaei G, Shibuya K, Adair-Rohani $\mathrm{H}$, et al. A comparative risk assessment of burden of disease and injury attributable to 67 risk factors and risk factor clusters in 21 regions, 1990-2010: a systematic analysis for the Global Burden of Disease Study 2010. The Lancet. 2013;380(9859):2224-60. [Full Text | DOI]

20. Msyamboza KP, Ngwira B, Dzowela T, Mvula C, Kathyola $\mathrm{D}$, Harries $\mathrm{AD}$, et al. The burden of selected chronic non-communicable diseases and their risk factors in Malawi: nationwide STEPS survey. PLoS One. 2011;6(5):e20316. [PubMed | Full Text]

21. Whiting DR, Guariguata L, Weil C, Shaw J. IDF diabetes atlas: global estimates of the prevalence of diabetes for 2011 and 2030. Diabetes Res Clin Pract. 2011 Dec;94(3):311-21. [PubMed | Full Text] 